\title{
Comparison of Three Different Two-equation Turbulence Models in Predicting Narrow Trench Film Cooling Effectiveness
}

\author{
Antar M.M. Abdala \\ Harbin Engineering University, Harbin \\ 150001, China \\ antar451@yahoo.com
}

\author{
Fifi N.M. Elwekeel \\ Harbin Engineering University, Harbin \\ 150001, China \\ fifinew2000@yahoo.com
}

\author{
Qun Zheng \\ Harbin Engineering University, Harbin \\ 150001, China \\ zhengqun@hrbeu.edu.cn
}

\begin{abstract}
In this study, three turbulence models k- $\varepsilon$, standard k$\omega$ and SST Gamma Theta which all available in ANSYS CFX were used. Gamma Theta Model is the recommended transition model for general-purpose applications. The full transition model is based on two transport equations, one for the intermittency and one for the transition onset criteria in terms of momentum thickness Reynolds number. Narrow trench configuration is used to predict the improvements in film cooling performance. Blowing ratios in the range $(0.5,1$ and1.4) were investigated. The results compared with experiments at different blowing ratios. Comparison of results with the $k-\varepsilon$ model indicates that each SST Gamma Theta and k- $\omega$ models predict circulations inside trench equally well at $M=1$. Over the surface, at low blowing ratios all models in case lateral spreading are under predicted, but SST Gamma Theta model shows some improvements in prediction than k- $\omega$. At high blowing ratios, SST Gamma Theta model offers good prediction in centerline with experiment than others, but all models show under predicted in lateral direction.
\end{abstract}

Keywords-Gas turbine; Narrow trench; Film cooling; Adiabatic effectiveness; Jet interaction phenomena

\section{INTRODUCTION}

Gas turbine blades need to be effectively cooled to increase component life and reduce maintenance costs. Typically, cooling a turbine blade involves long turbulated serpentine internal passages with ribs, impingement holes, and pin fins for heat transfer enhancement along with film cooling through discrete holes to protect the blades from direct contact with hot gases. With increasing turbine inlet temperatures, modern hot gas path components may be coated with thin layers of thermal barrier coatings (TBC) made of ceramic material, such as Yttria with stabilized Zirconia. The coatings are thin and on the order of film hole sizes typically $0.5-2 \mathrm{~mm}$. typically, film holes are drilled on the surface before the TBC layer is applied. The hole area may be masked, then the TBC layer is sprayed, and then the mask will be removed revealing the holes embedded in 2D trenches Lu et al.[1].Gas turbine efficiency can be significantly increased by cooling technologies. Shaped holes have proven to provide the highest adiabatic effectiveness among film cooling configurations but are expensive to manufacture. Certain configurations of cylindrical holes embedded in transverse trenches have been shown to perform similarly to shaped holes, and trenches would be cheaper to manufacture than shaped holes. Trench performance is highly dependent on the configuration, so investigating variations in depth, width, and shape is important to maximize trench effectiveness. Several studies have investigated various trench configurations. Bunker [2], Waye and Bogard [3], Lu et al [4] and Harrison and Bogard [5] studied film holes embedded in trenches.

Their results showed that the film cooling holes provide higher film effectiveness when embedded in a trench and the narrow trench configuration provided the best adiabatic effectiveness performance. Zuniga and Kapat [6] studied effect of increasing pitch-to-diameter ratio on the film cooling effectiveness of shaped and cylindrical holes embedded in trenches. The trenching case has been shown to significantly increase film coverage this study.

Renze et al. [7], investigated holes embedded in a shallow cavity using large-eddy simulation (LES). Harrison and Bogard [5] used $\mathrm{k}-\varepsilon$ turbulence model depending on the literatures survey outcomes of simple hole although that their studies were holes embedded in trenches. Trenches complicated than simple hole with highly unsteady process generating complex vortical structures, therefore there are different effects on mechanisms of the momentum and heat exchange between the jet and the cross flow.

The k- $\omega$ model has the advantage near the walls to predict the turbulence length scale accurately in the presence of adverse pressure gradient. The k- $\omega$ model does not involve the complex non-linear damping functions required for the $\mathrm{k}-\varepsilon$ model and is therefore more accurate and more robust. The k- $\omega$ based SST model accounts for the transport of the turbulent shear stress and gives highly accurate predictions of the onset and the amount of flow separation under adverse pressure gradients by the inclusion of transport effects into the formulation of the eddyviscosity.

As noted above, k- $\omega$ and SST Gamma Theta turbulence models not available in studying narrow trench. So, in this study narrow trench was investigated by using $\mathrm{k}-\varepsilon, \mathrm{k}-\omega$ and SST Gamma Theta turbulence models which all available in ANSYS CFX code. Several computational studies have compared adiabatic effectiveness simulations to experiments. 


\section{NOMENCLATURE}

\begin{tabular}{|l|l|}
\hline $\mathrm{D}$ & Hole diameter $(\mathrm{m})$ \\
\hline $\mathrm{DR}$ & Density ratio of coolant to mainstream, $\rho_{\mathrm{c}} / \rho_{\infty}(-)$ \\
\hline $\mathrm{L}$ & Hole length $(\mathrm{m})$ \\
\hline $\mathrm{M}$ & $\begin{array}{l}\text { Blowing ratio of coolant to mainstream }(-) \\
\mathrm{M}=\mathrm{DR} * \mathrm{U}_{\mathrm{c}} / \mathrm{U}_{\infty}\end{array}$ \\
\hline $\mathrm{P}$ & Hole spacing $(\mathrm{m})$ \\
\hline $\mathrm{S}$ & Trench depth $(\mathrm{m})$ \\
\hline $\mathrm{T}$ & Temperature $(\mathrm{K})$ \\
\hline Tu & Mainstream turbulence intensity $(\%)$ \\
\hline $\mathrm{W}$ & Trench width $(\mathrm{m})$ \\
\hline $\mathrm{X}$ & Streamwise coordinate along model surface \\
\hline $\mathrm{Y}^{+}$ & Non-dimensional wall distance \\
\hline Greek symbols \\
\hline$\Lambda$ & Turbulence length scale \\
\hline$\alpha$ & Coolant injection angle $($ deg. $)$ \\
\hline$\eta$ & Adiabatic effectiveness, $\left(\mathrm{T}_{\infty}-\mathrm{T}_{\mathrm{aw}}\right) /\left(\mathrm{T}_{\infty^{-}}-\mathrm{T}_{\mathrm{c}}\right)$ \\
\hline$\theta$ & Non-dimensional temperature ratio, $\left(\mathrm{T}_{\infty}-\mathrm{T}\right) /\left(\mathrm{T}_{\infty}-\mathrm{T}_{\mathrm{c}}\right)$ \\
\hline$\rho$ & Density $\left(\mathrm{kg} / \mathrm{m}^{3}\right)$ \\
\hline Subscripts \\
\hline$\infty$ & Mainstream \\
\hline aw & Adiabatic wall \\
\hline $\mathrm{c}$ & Coolant \\
\hline
\end{tabular}

\section{COMPUTATION SETUP}

An outline of the geometry for the narrow trench with dimensions of computational domain is illustrated in Fig. 1. Accuracy of solutions is strongly dependent upon the quality of the grid system in minimizing grid-induced errors and in resolving the relevant flow physics. In this study, a grid sensitivity study was carried out to determine the appropriate grid. In this study three grids - the baseline grid with 1.6 million cells, a finer grid with 2.9 million cells (adaptation 1), and a still finer grid with 3.5 million cells (adaptation 2) are investigated. For the two finer grids, the additional cells were all concentrated about the film-cooling hole and the hot gas/coolant jet interaction region, where the flow physics is most complicated. From this grid sensitivity study, the baseline grid was found to give essentially the same result for the lateral adiabatic effectiveness as those from adaptation 1 and 2 grids. The final mesh sizes of narrow trench varied from 2.9-3.2 million cells depending on configuration and blowing ratio as shown in Fig. 2. Simulation conditions are presented in Table 1. The results obtained in the current study were generated using ANSYS CFX code and $\mathrm{k}-\varepsilon, \mathrm{K}-\omega$ and SST Gamma Theta turbulence models were utilized. A very fine region of cells was created on the walls to approximate $\mathrm{Y}^{+}$values less than unity. The convergence criterion was set to RMS residuals of $1 * 10^{-5}$.

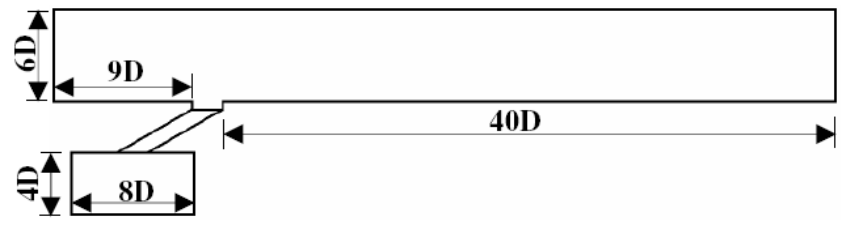

Fig.1 (a) Dimensions of computational domain

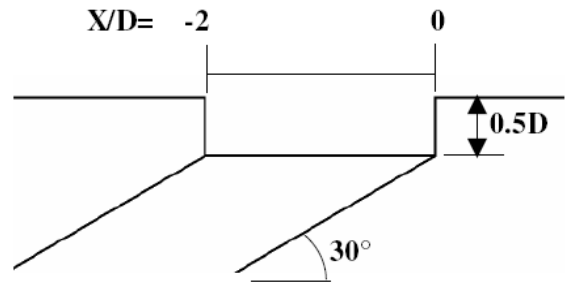

Fig.1 (b) Test section

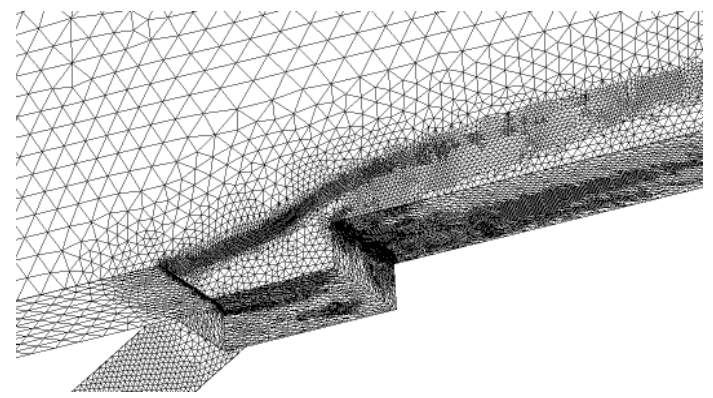

Fig. 2 Computational grid for narrow trench at $\mathrm{M}=0.5$

TABLE 1 SIMULATION PARAMETER CONDITIONS

\begin{tabular}{|l|l|}
\hline $\boldsymbol{D}$ & $4.11(\mathrm{~mm})$ \\
\hline $\boldsymbol{a}$ & $30^{\circ}$ \\
\hline \multirow{2}{*}{$\boldsymbol{L} / \boldsymbol{D}$} & 5.7 (with trenches) \\
\cline { 2 - 2 } & 6.7 (without trenches) \\
\hline $\boldsymbol{P} / \boldsymbol{D}$ & 2.775 \\
\hline $\boldsymbol{S} / \boldsymbol{D}$ & 0.5 \\
\hline $\boldsymbol{D} \boldsymbol{R}$ & 1.3 \\
\hline $\boldsymbol{W} \boldsymbol{D}$ & $2 \mathrm{D}$ \\
\hline $\boldsymbol{M}$ & $0.5,1$ and 1.4 \\
\hline Mainstream conditions \\
\hline $\boldsymbol{T} \boldsymbol{u}$ & $1 \%$ \\
\hline $\boldsymbol{A} / \boldsymbol{D}$ & 0.42 \\
\hline $\boldsymbol{U} \infty$ & $30.82(\mathrm{~m} / \mathrm{s})$ \\
\hline $\boldsymbol{T}$ & $300(\mathrm{~K})$ \\
\hline $\mathbf{C o o l a n t}$ conditions \\
\hline $\boldsymbol{T} \boldsymbol{u}$ & $2 \%$ \\
\hline $\boldsymbol{A} / \boldsymbol{D}$ & 0.56 \\
\hline $\boldsymbol{T}$ & $230.77(\mathrm{~K})$ \\
\hline
\end{tabular}

All flow inlets were defined as velocity inlets, while the outlet was defined as a pressure outlet. Due to symmetry, the model was cut along its half-plane and a symmetry boundary condition was applied. The left side was assigned walls with free slip conditions. All remaining plane were assigned adiabatic walls with no slip conditions. Air was taken as a working fluid, since density variation is significant over this temperature range; the density was modeled as a function of temperature according to the following equation:

$$
\rho=\frac{P}{R * T}
$$

where, $\mathrm{P}$ is the reference pressure $(101325 \mathrm{~Pa}), \mathrm{R}$ is gas constant $\left(287 \mathrm{~J} \mathrm{~kg}^{-1} \mathrm{~K}^{-1}\right)$. The plenum inlet velocity was varied to simulate different blowing ratios. The temperature was set to $230.77 \mathrm{~K}$ to obtain a density ratio of $\mathrm{DR}=1.3$. 


\section{RESULTS}

In the present work, the computational domain was validated by experimental work. Contours and thermal profiles were drawn.

Comparisons for narrow trench with experimental work Waye and Bogard [5] was shown in Figs. 3-5. At low blowing ratio $M=0.5$, the narrow trench simulation agreed very well with experimental findings. $\mathrm{k}-\omega$ turbulence model offers more realistic data than the others.

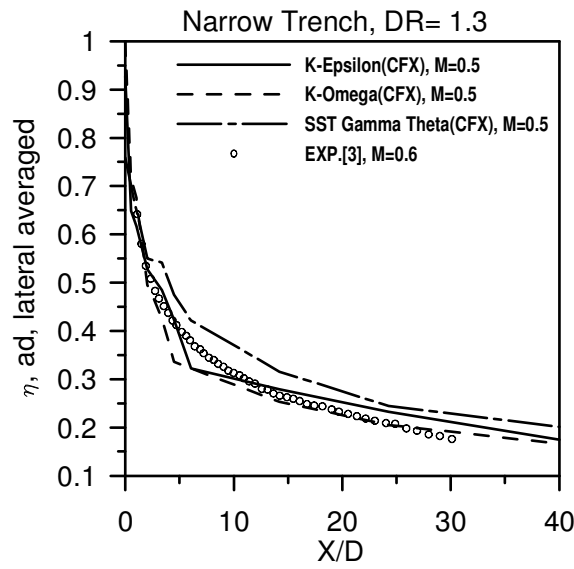

Fig. 3 Validation of narrow trench with experiment at $M=0.5$

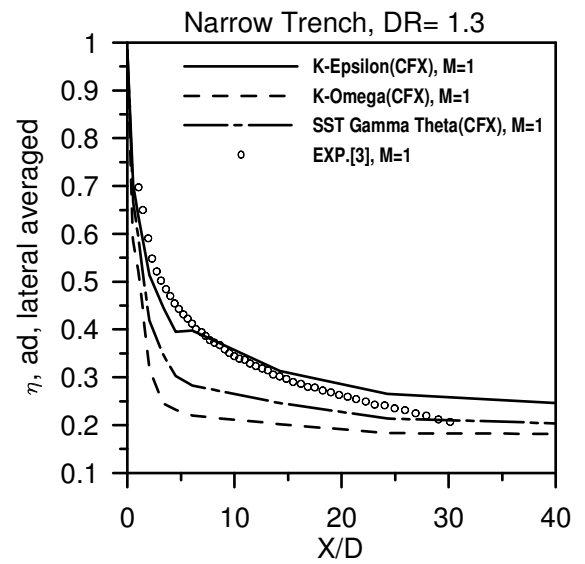

Fig. 4 Validation of narrow trench with experiment at $M=1$

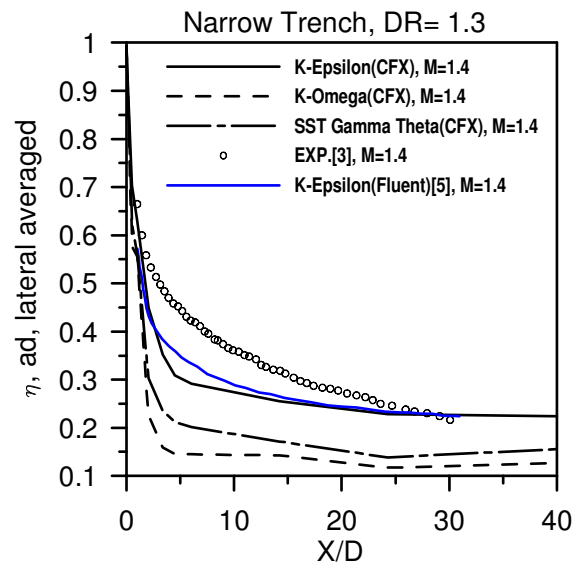

Fig. 5 Validation of narrow trench with experiment at $\mathrm{M}=1.4$
At moderate blowing ratio $\mathrm{M}=1, \mathrm{k}-\varepsilon$ turbulence model offers close data than others, but SST Gamma Theta model shows good prediction at $X / D>20$. at $M=1.4$, all turbulence models are under predicted data, while $\mathrm{k}-\varepsilon$ turbulence model predicted with experiments at X/D $>25$ and SST Gamma Theta model shows good results than $\mathrm{k}-\omega$ model.

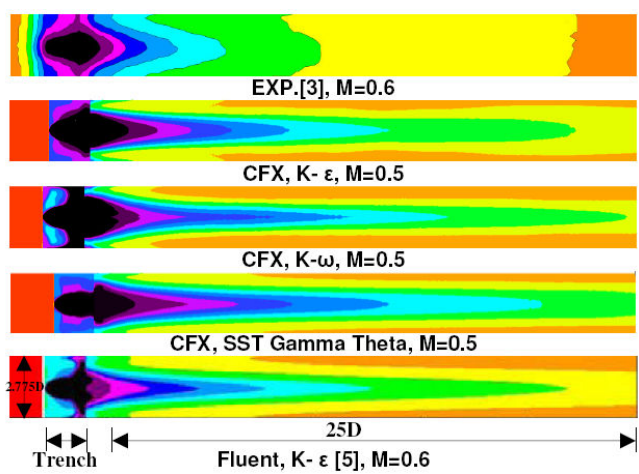

Fig. 6(a) Surface Contour Plots for the Narrow Trench at $\mathrm{M}=0.5$

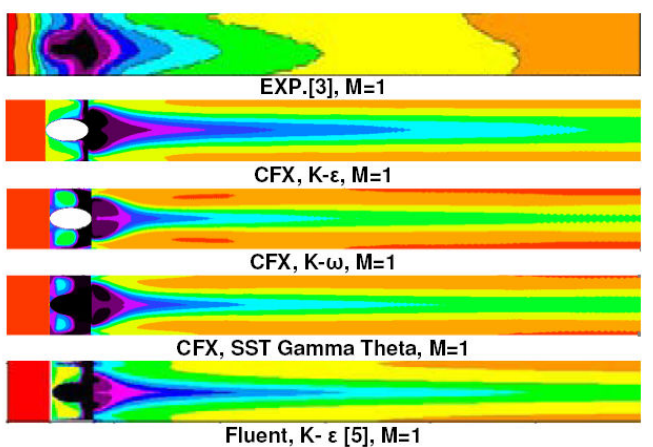

Fig. 6(b) Surface Contour Plots for the Narrow Trench at $M=1$

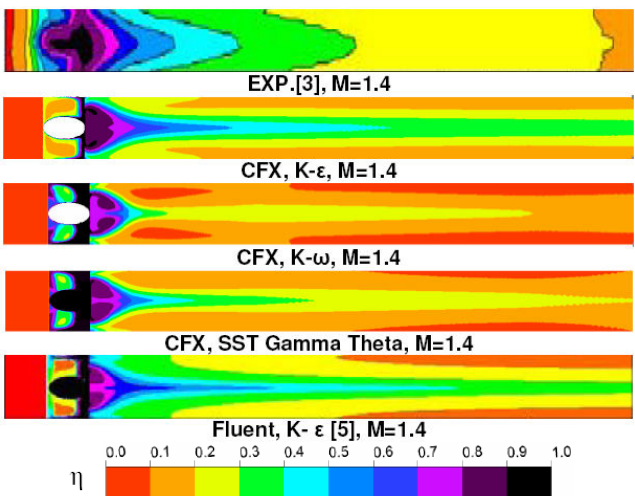

Fig. 6(c) Surface Contour Plots for the Narrow Trench at M =1.4

Computationally and experimentally determined contour plots of adiabatic effectiveness for the narrow trench are shown in Fig. 6. The simulations clearly under-predicted lateral spreading and over-predicted centerline effectiveness for narrow trench at $M=0.5$ and $M=1$ for all models, but SST Gamma Theta model shows some improvements in prediction with lateral spreading than $\mathrm{k}-\omega$. At $\mathrm{M}=1.4, \mathrm{k}-\varepsilon$ simulations under-predicted lateral spreading and over-predicted centerline effectiveness, while k- $\omega$ simulations offers under-predicted 
lateral and centerline effectiveness, but SST Gamma Theta model offers good prediction in centerline with experiment and under predicted in lateral direction.

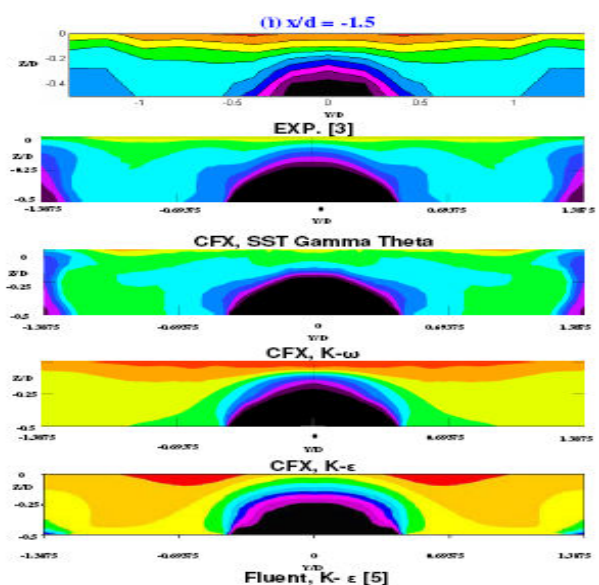

(a) $\mathrm{X} / \mathrm{D}=-1.5$
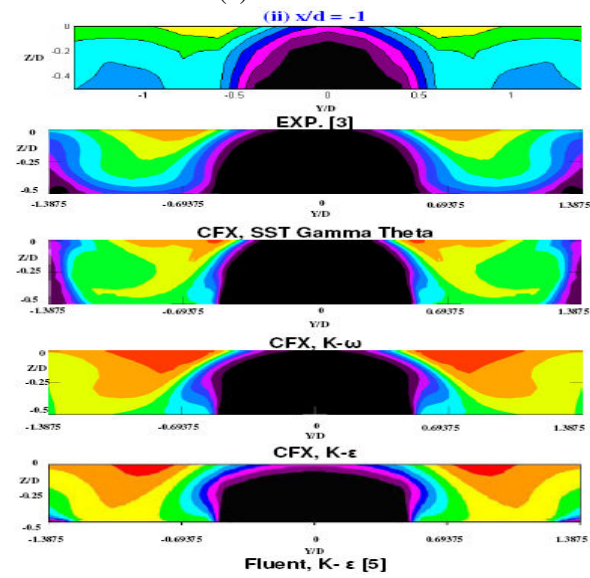

(b) $\mathrm{X} / \mathrm{D}=-1$
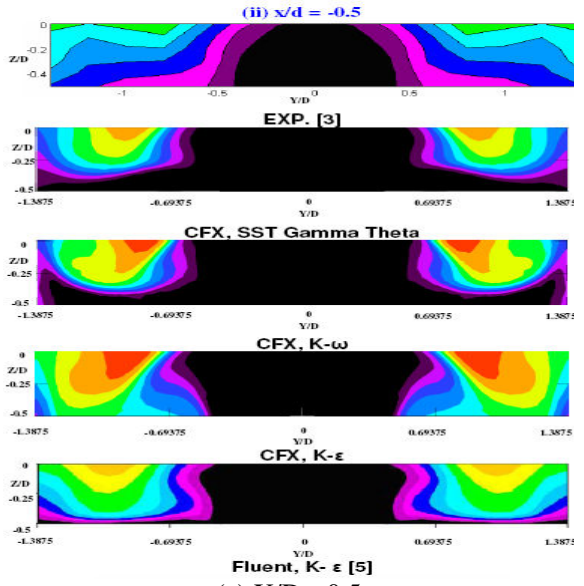

(c) $\mathrm{X} / \mathrm{D}=-0.5$
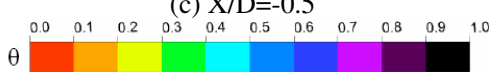

Fig. 7 Computational and experimental thermal profiles inside narrow trench at $\mathrm{M}=1.0$

Computational and experimental thermal profiles inside the trench are shown in Fig. 7. By examining this simulation, it is apparent that the coolant impacted the downstream trench wall and then the coolant spread in the trench and recirculated around the hole to the back of the trench. The measurements show more coolant recirculation occurring in the trench than simulations predicted by k- $\varepsilon$ turbulence model and very good agreement by SST Gamma Theta model than k- $\omega$ turbulence model at $\mathrm{M}=1$

\section{CONCLUSIONS}

In this study, computational simulations were made using ANSYS CFX to predict the improvements in film cooling performance for narrow trench configuration. Three turbulence models SST Gamma Theta, k- $\omega$ and k- $\varepsilon$ were used. The effects of blowing ratios on adiabatic film effectiveness are analyzed in detail. Results from the validation cases indicate that each SST Gamma Theta and k- $\omega$ models is better suited to adverse pressure gradient flow calculations than $\mathrm{k}-\varepsilon$ turbulence model especially inside trench.

\section{REFERENCES}

[1] Lu, Y., Dhungel, A., Ekkad, S. V., and Bunker, R.S., 2009, "Effect of Trench Width and Depth on Film Cooling From Cylindrical Holes Embedded in Trenches" ASME Journal of Turbo machinery, Vol. 131, pp. 1-13.

[2] Bunker, R., 2002, "Film Cooling Effectiveness due to Discrete Holes within a Transverse Trench", ASME paper GT2002-30178.

[3] Waye, S. and Bogard, D., 2006, "High Resolution of Film Cooling Effectiveness Measurements of Axial Holes Embedded in a Transverse Trench with Various Trench Configurations", ASME Paper GT200690226.

[4] Lu, Y., Nasir, H., and Ekkad, S. V., 2005, "Film Cooling From a Row of Holes Embedded in Transverse Slots," ASME Paper GTI2005-68598.

[5] Harrison, K. L. and Bogard, D. G., 2007, "CFD Predictions of Film Cooling Adiabatic Effectiveness for Cylindrical Holes Embedded in Narrow and Wide Transverse Trenches", ASME Paper GT2007-28005.

[6] Zuniga, H. A. and Kapat, J. S., 2009, "Studied Effect of Increasing Pitch-To-Diameter Ratio on The Film Cooling Effectiveness of Shaped and Cylindrical Holes Embedded in Trenches", ASME Paper GT200960080.

[7] Renze, P., Schroder, W., and Meinke M., 2008, “ Large-eddy Simulation of Film Cooling Flow Ejected in a Shallow Cavity", ASME Paper, GT2008-50120. 